CAHIER DE RECHERCHE \#1614E

WORKING PAPER \#1614E

Département de science économique

Department of Economics

Faculté des sciences sociales

Université d'Ottawa

Faculty of Social Sciences

University of Ottawa

\title{
Are Quebecers More Stressed Out at Work than Others? An Investigation into the Differences between Quebec and the Rest of Canada in the Level of Work Stress *
}

\author{
Golnaz Sedigh ${ }^{\dagger}$, Rose Anne Devlin ${ }^{\ddagger}$ and Gilles Grenier ${ }^{\S}$
}

September 2016

\footnotetext{
* This paper substantially modifies the PhD thesis of Golnaz Sedigh. We thank Pierre Brochu, Catherine DeriArmstrong, Jennifer Stewart, Tammy Schirle and Pierre Fortin for comments on an earlier version. Golnaz Sedigh is the first author, thereafter the order is alphabetic.

† Department of Economics, University of Ottawa, 120 University Private, Ottawa, Ontario, Canada, K1N 6N5; email: golnaz80@gmail.com.

₹ Department of Economics, University of Ottawa, 120 University Private, Ottawa, Ontario, Canada, K1N 6N5; email: radevlin@uottawa.ca.

$\S$ Department of Economics, University of Ottawa, 120 University Private, Ottawa, Ontario, Canada, K1N 6N5; email: Gilles.Grenier@uottawa.ca.
} 


\begin{abstract}
Stress at work is costly to individuals as well as employers, causing productivity to suffer and worker compensation claims to increase. Irrespective of how the data are grouped, individuals in Quebec are much more likely to report high work stress relative to those in any other Canadian province. Here we explore why this might be the case. Using pooled cross-sectional data from eight cycles of the Canadian Community Health Survey, spanning 2003-2012, we show that several factors are related to work stress, including chronic diseases, mental health, and lifestyle choices like smoking and drinking. Nevertheless, living in Quebec is persistently associated with higher reported work stress. We discuss whether contextual factors, like Quebec's child-care policy and its legal regime may help us understand this result better; a 'cultural' explanation is explored, as is the possibility that Quebecers simply report more stress. While residents of Quebec do not appear to differ from others with respect to the prevalence of some 'stress-related' health conditions - pointing to a cultural component to the explanation - they are absent from work more often than others, suggesting that the costs to Quebec of this phenomenon are real.
\end{abstract}

Key words: Work stress, Canadian Community Health Survey, interprovincial comparisons of stress, Quebec, Canada.

JEL Classification: J28, J08.

\title{
Résumé
}

Est-ce que les Québécois sont plus stressés au travail que les autres ? Une étude des différences entre le Québec et le Reste du Canada dans le niveau de stress au travail.

Le stress au travail coûte cher aux individus et aux employeurs car il diminue la productivité et augmente les demandes d'indemnisation pour accidents de travail. Quelle que soit la façon dont les données sont regroupées, les Québécois déclarent toujours plus de stress au travail que les résidents des autres provinces canadiennes. Nous explorons les raisons de ce phénomène. À l'aide de données empilées de huit cycles de L'Enquête sur la santé dans les collectivités canadiennes couvrant les années 2003 à 2012, nous montrons que plusieurs facteurs sont reliés au stress, dont les maladies chroniques, la santé mentale et les habitudes de consommation de tabac et d'alcool. Néanmoins, le fait de vivre au Québec est constamment associé à un plus grand stress au travail. Nous discutons du rôle possible de facteurs contextuels, comme la politique de garde d'enfants et le régime juridique du Québec. Nous explorons aussi une explication "culturelle " de même que la possibilité que les québécois aient simplement tendance à déclarer plus de stress. Alors que les résidents du Québec ne semblent pas différer des autres en ce qui concerne la prévalence de troubles de santé « liés au stress »-ce qui suggère un volet culturel à l'explication -, ils sont absents du travail plus souvent que les autres, ce qui laisse supposer que les coûts au Québec de ce phénomène sont réels.

Mots clés : Stress au travail, Enquête sur la santé dans les collectivités canadiennes, comparaisons interprovinciales de stress, Québec, Canada.

Classification JEL : J28, J08. 


\section{Introduction}

For many individuals, work stress is a fact of life. About 30 percent of Canadians experience a high level of stress at work, estimated to result in losses of some $\$ 33$ billion every year from absenteeism and low productivity (Bickford, 2005; Bernèche, 2010). Health-care expenditures are nearly 50 percent greater for workers with high levels of stress than for those with lower levels of stress (Williams, 2003, p1), and about 30 percent of disability claims are work-stress related in Canada (Connor, 2005). In short, work stress is a problem not only for the individuals experiencing it, but for society at large.

If we look at work stress figures across Canadian provinces one fact stands out: people in Quebec report significantly higher levels of work stress than people in all other jurisdictions in Canada. A picture helps to illustrate this phenomenon. Using all nine cycles of the Canadian Community Health Survey (CCHS) spanning 2001 to 2012, figure 1 shows the percentage of respondents who report "quite a bit" or "extreme" stress in their workplace. No matter the year, individuals in Quebec (the plain line at the top) report significantly more stress than those in any other province. But why?

\section{FIGURE 1 HERE}

Many factors contribute to stress in the work place, including demographic, socioeconomic, health, work environment, social support, and culture (e.g., Summers et al., 1995; Hendrix et al., 1995; Cooper, 1998; Barling et al., 2005; and Dolan, 2007). Women have been found to have higher work stress than men, possibly because they do more children caring than men in addition to other responsibilities at home (Wilkins and Beaudet, 1998; Michie, 2002; Williams, 2003; Bellavia and Frone, 2005; and Park, 2007). Economic factors related to work stress include education, income, working hours, shift 
work, part-time/full time job, occupation, self-employment, unionization and unemployment (Burke and Richardsen, 1990; Fenwick and Tausig, 1994; Wilkins and Beaudet, 1998; Park, 2007, 2008; Williams, 2003; Heisz and LaRochelle-Côté, 2006).

Chronic diseases put more pressure on work life including concerns about future unemployment, contributing to work stress levels (Barnes-Farrell, 2005). Michie (2002) argues that coping with stress can alter life-style choices like smoking, drinking and physical activities that affect health. High strain jobs, low social supports at work, job dissatisfaction, job insecurity and physically demanding jobs have all been found to affect the level of work stress (Michie, 2002; Williams, 2003; Park, 2007). An individual's social support, like the sense of belonging to the community, can make a difference when it comes to managing stress at work (Choenarom et al., 2005; Park, 2007).

Perhaps less obvious is the potential role played by cultural factors. Probst (2005), in reviewing several studies on this topic, suggests that cultural values cause people to react differently to job insecurity, explaining that people with a "collectivist cultural orientation" are more likely to report work stress because of job insecurity than "individualistic" people. Liu and Spector (2005) demonstrate that people from different cultures have different perceptions about the level of work stress, with, for instance, formal rules being more important in some cultures than in others.

Quebec is different than the other jurisdictions in Canada on a number of fronts, including health care (the only province to have a program of universal prescription drug insurance), day care (which is heavily subsidized), legal system (civil law as opposed to common law in the Rest of Canada) and, of course, language, where French is the majority language as opposed to English elsewhere. The observation that Quebecers consistently 
report more job stress than other Canadians is puzzling. Maybe individuals in Quebec are simply more predisposed to report being stressed relative to others? Could it be that individuals in Quebec are more satisfied with life but more stressed at work? Could it be linked to the characteristics of the population? Perhaps provincial institutional differences, like those associated with legal regimes or child-care policies, can help explain this phenomenon? This paper aims to make two main contributions: It is the first to look specifically at the differences between Quebec and other Canadian provinces in the level of reported work stress, with the view to trying to explain why this difference persists. Secondly, we add to the literature on the determinants of work stress by including several hitherto ignored variables reflecting language and culture, to see whether these can help us understand better work stress in Quebec and beyond.

After including a rich variety of variables, and of estimating several specifications of the model, living in Quebec remains positively associated with reporting high work stress. We explore several avenues to help understand better why this result persists. We find, for instance, that Anglophones in Quebec are a little less stressed than Francophones, but stressed nevertheless. Quebecers also report higher levels of life stress, so we looked at whether what we are picking up is simply a tendency to 'complain' more. We highlight that Quebecers' anxiety seem to be more around relationships than around matters such as finance or health - which suggested that differences in the civil law treatment of commonlaw marital relationships (two people living together as a couple but not legally married to each other) may help explain some of this phenomenon. The fact that we were unable to detect any major differences between the prevalence of stress-related disorders and residents of Quebec and elsewhere, suggests that some of the stress may be related to 
reporting rather than objective stress levels. But, Quebecers are much more likely to be absent from work, so the potential costs of this work stress are real; policies and strategies to assist in improving this situation are called for.

\section{Data and Summary Statistics}

We use eight cycles of the Canadian Community Health Surveys (CCHSs) between 2003 and 2012, and the Canadian Community Health Survey- Mental Health cycle 2012 to investigate work stress in Quebec and other provinces. A wide-range of information is gathered in these surveys, including responses to a question about level of stress at work. If respondents report that most of their work days have been quite a bit or extremely stressful in the past 12 months, they are identified as people with high work stress. If respondents report that most days have been not at all, not very or a bit stressful in the main job or business in the past 12 months, they are identified as having low work stress (we also run regressions omitting the middle "a bit stressful" response). This way of categorizing individuals based on self-reported work stress has been used in other studies as well (e.g., Park, 2007, 2008; Bordeleau and Traoré, 2007; and Crompton, 2011).

In addition to the stark visual presented in figure 1, we looked at levels of reported work stress by sex, age, health, education, income, working hours, marital status, immigration status and mother tongue. No matter how we parse the data, individuals in Quebec report higher work stress than those living elsewhere. For instance, figures 2 and 3 depict gender and work stress, and income and work stress for the period 2001-2012: it is clear that Quebecers are reporting significantly more work stress than those in Ontario (our largest province) and those in the other provinces (referred to as Rest of Canada).

FIGURES 2 AND 3 HERE 
The main independent variable of interest in this study is binary, taking the value one if the respondent lives in the province of Québec and zero otherwise. Two other binary variables represent those who live in the province of Ontario and those living in the Rest of Canada. The eight provinces in the Rest of Canada are the base group.

Data are pooled from CCHS 2003, 2005, 2007, 2008, 2009, 2010, 2011 and 2012, and the sample is restricted to individuals aged 15-65 of whom the work stress question is asked. Starting with a sample of 463,758 observations for this age group, we remove individuals from the Territories (and are left with $n=451,398$ ); we exclude those with missing information on age and marital status (leaving us with $n=439,712$ ) and remove those who did not report personal income or household income (resulting in $n=299,196$ ). Finally, excluding those who did not answer questions regarding other variables such as education and working hours left us with a final sample of 259,841 usable observations: 75,224 with high work stress, 184,617 with low work stress; 54,739 from Québec, 88,888 from Ontario and 116,214 from the Rest of Canada. ${ }^{1}$

Table 1 reports the mean values of the selected variables in our sample using the pooled data (2003-2012). They are categorized into the following groups: personal characteristics, work characteristics, family characteristics, and health and personal behaviour characteristics. Several stark differences between Quebec, Ontario and the Rest of Canada (RoC) are revealed, the main one being the number of individuals reporting high work stress: 37.8 percent in Quebec, 28.7 percent in Ontario and 26.4 percent elsewhere. Other notable differences include the proportion of the population living in a Census

\footnotetext{
${ }^{1}$ All the regressions and descriptive analysis are weighted using the person weight variable: WGHT_M. Weights are also normalized in each survey to add up to one in order to give equal weights to each survey when the data are pooled.
} 
Metropolitan Area in Ontario ( 80 percent) relative to Quebec (70 percent) and the RoC (61 percent); fewer people are legally married in Quebec (37 percent) and many more people live in a common-law marital relationship in that province ( 29 percent) relative to the other jurisdictions (although the rate when married and common-law are added together is very similar across the three areas). Ontario is home to many more immigrants than the other jurisdictions and hence more visible minority individuals. Obviously, large linguistic differences are present. Average personal income and hours worked are lower in Quebec than in the other two areas. Individuals in Quebec are relatively more likely to consume alcohol regularly, are more inactive, and have a lower sense of belonging to their communities.

\section{TABLE 1 HERE}

\section{Methodology}

A probit model is employed to investigate the difference in the level of work stress between Quebec, Ontario and the Rest of Canada, as follows:

$H W S^{* i}{ }_{\mathrm{j}}=Z_{j}^{i} \beta+\epsilon_{1 j}^{i} \quad \mathrm{j}=\operatorname{group}$

$H W S^{* i}$ is a continuous latent variable denoting actual work stress for individual $i$ belonging to group $j$. As is usual with the probit model, we observe only $H W S^{i}$, a dummy variable taking the value 1 if $\epsilon_{1}{ }^{i}>-Z^{i} \beta$ and 0 if $\epsilon_{1}{ }^{i} \leq-Z^{i} \beta$.

$Z_{j}^{i}$ is a vector of independent variables that affect high work stress (including a constant term). It includes the personal characteristics, work characteristics, family characteristics and health and personal behaviour characteristics shown in table 1 , in addition to three locational dummies (Quebec, Ontario and the Rest of Canada) and one CMA indicator. In the basic specifications, we include the variables that are available in 
all the cycles of the survey. In additional sensitivity tests, the model is re-estimated with various extra factors, some of which are available in only specific survey cycles. To test whether living in Quebec affects the level of work stress differently across groups, equation (1) was also estimated for males and females, immigrants and non-immigrants, and Anglophones and Francophones. We focus mainly on the full sample, but make reference to these other estimations when appropriate.

\section{Results}

The marginal effects from the probit model of equation (1) for the full sample are provided in table 2 ; they are evaluated at the means of the explanatory variables. The model is also estimated for several sub-samples, to which we refer when necessary.

\section{TABLE 2 HERE}

\subsection{Work Stress in Quebec}

The variable of interest is "Quebec". We report the estimated marginal effects from all of the independent variables in the main model, pooling together males and females, in table 2. The estimated coefficient on the Quebec dummy variable is positive and statistically significant: residents of Quebec are 8.1 percentage points more likely to report work stress relative to those in the eight provinces which constitute the reference group (Rest of Canada), and over six points more likely relative to those in Ontario.

Several specifications of this main model were estimated. Table 3 presents the marginal effects associated with the regional dummy variables for five such specifications, including the one reported in table 2 to ease comparison (column (4)). For space reasons, we do not report the marginal effects from all of the included variables, we simply indicate for which categories of variables we controlled. Column (1) is the most parsimonious 
specification which includes only personal characteristics (and year fixed effects); column (2) adds work characteristics to the specification; column (3) adds family characteristics; and columns (5) and (6) separate out the main model of (4) by men and women. Irrespective of the specification, the estimated effect of residing in Quebec is positive and statistically significant. Moreover, adding independent variables does not reduce the strength of the Quebec effect, rather to the contrary - with the most parsimonious specification having an estimated effect of 0.069 attached to the Quebec variable, and the least, 0.081. Finally, we see in the last two columns of table 8 that men in Quebec are more likely to report being stressed at work than are women: 8.9 points versus 7.1 .

\section{TABLE 3 HERE}

Table 4 presents the main specification (from table 2) parsed into immigrant and non-immigrant groups, and Anglophone and Francophone groups. Again, it is notable that the estimated coefficient on Quebec is positive and statistically significant. It is the lowest for the immigrant group: immigrants in Quebec are 4.6 percentage points more likely to report stress at work relative to immigrants in the RoC (excluding Ontario), and 2.8 points more likely when compared to those in Ontario. Non-immigrants in Quebec are 9.5 percentage points more likely to report stress at work relative to non-immigrants in $\mathrm{RoC}$ (excluding Ontario), which drops to 7.6 when compared to non-immigrants in Ontario. Finally, the last two columns of table 4 reveal that Anglophones in Quebec are more likely to report work stress than Anglophones living elsewhere, and that Francophones in Quebec are even more likely to report work stress than their counterparts elsewhere. Taken together, these finding suggest that the Quebec context matters for both English and French speakers, but it matters more for the latter than the former. In other words, the 
Quebec/Francophone culture can explain part of the difference between the reported levels of work stress in Quebec and in the Rest of Canada.

\section{TABLE 4 HERE}

To see whether the higher level of stress in Quebec is generalizable across this province, or is particular to given regions, we estimated probit models of work stress for each of the six regions of Quebec: Saguenay; Quebec City; Sherbrooke; Trois Rivieres; Montreal; and non-Census Metropolitan Areas (CMAs). Table 5 presents the estimated marginal effects for the location variables by these six regions (same specification as in table 2). While there are some differences in the magnitudes of the effects - ranging from a high of 10.3 percentage points in Quebec City to a low of 7.2 in Sherbrooke - no matter where one lives in Quebec, workers are reporting higher levels of stress when compared to their counterparts elsewhere.

\section{TABLE 5 HERE}

As an additional robustness $\mathrm{check}^{2}$, we ran ordered probit models where the dependent variable took on five values regarding work stress: not at all stressful (1), not very stressful (2), a bit stressful (3), quite a bit stressful (4) and extremely stressful (5). In this case, we found that people in Quebec are 1.8 percentage points less likely than the Rest of Canada to report not at all stressful; 2.4 percentage points less likely to report not very stressful; 0.35 percentage points less likely to report a bit stressful; and then 3.3 and 1.4 percentage points more likely to report stress in the two highest categories, corroborating our previous findings. As a further check, we ran the dichotomous probit model but eliminated the middle category (3). In this case, our results are stronger:

\footnotetext{
${ }^{2}$ The detailed regressions for this and the following analyses can be obtained from the authors.
} 
residents of Quebec are 11.2 points more likely to report being stressed than those in the Rest of Canada (as opposed to 8.1 reported earlier). Making a clearer distinction between the stressed and not stressed groups renders our results even starker.

We also estimated the probit model for each year separately to see if we could observe differences in the estimated coefficient on the Quebec dummy variable over time. No clear pattern was discernable. The estimated coefficients were always positive and statistically significant and tended to be larger in the latter years relative to the earlier ones. In other words, there is no evidence that this persistent difference in the work stress reported in Quebec is tapering off over time (as was found by Barrington-Leigh (2013) when analyzing differences in life satisfaction across jurisdictions - a point to which we return later).

Some cycles of the CCHS collected additional information that may help to explain work stress, including whether or not the individual engaged in shift work as well as other work environment variables and social support variables. These variables are not available in all of the surveys and adding them reduces considerably the number of observations in some samples. Table 6 presents the estimated marginal effects from the province (region) dummy variables for eight specifications: column (1) is again the base case (from table 2); column (2) reports the results when we add seven variables about shift work to the base case; column (3) adds working part-time to the base case; column (4) adds seven variables about work environment to the base case; column (5) adds two controls for mental health problems; column (6) adds four controls for social support; column (7) adds controls for quality and availability of health care; finally, column (8) presents the marginal effects from a specification that adds extra provincial information on regional average hours 
worked, regional average weekly earnings, and regional unemployment durations. Irrespective of the specification, the probability of reporting high work stress is higher in Quebec than in Ontario and the Rest of Canada. We were intrigued by specification (6) which controlled for social support because this reduced significantly the marginal impact of living in Quebec on work stress. But this result seems to arise because of the muchreduced sample size, rather than from the inclusion of social support variables.

\section{TABLE 6 HERE}

\subsection{Other Factors influencing Work Stress}

The results presented in table 2 (and those underlying the coefficients reported in tables 3 to 6 ) point to a number of other factors that are associated with work stress. Across the board, stress increases with age at a decreasing rate; separated, widowed and divorced people are more stressed as are those in a common-law marital relationship. Living in a CMA increases the probability of having high work stress by two percentage points. There is a higher chance of having high work stress among Francophones than among Anglophones, irrespective of where they live.

Similar to other studies, table 2 reveals that higher education and higher income are correlated with high work stress (e.g., Park, 2007). People with post-secondary degrees have a higher probability (five percentage points) of having high work stress. A one thousand dollars increase in personal income increases the probability of having work stress by 0.1 percentage points. Working longer hours is associated with increased work stress (Michie, 2002; LaRochelle-Côté, 2006), which is notable given than workers in Quebec have among the lowest average hours of work per week. Being a student and 
working at the same time adds about four percentage points to the probability of having work stress relative to working non-students.

Reported work stress is 8.4 percentage points higher for those with poor/fair health than for those in excellent health. Much higher work stress (16 percentage points) is reported by those with poor/fair mental health when compared to those with excellent/good/very good mental health. Smokers report more stress than non-smokers, and regular drinkers are 1.4 percentage points more likely to report high stress. A very weak sense of belonging to community is associated with a three percentage point increase in the probability of reporting work stress relative to their strong sense of belonging counterparts.

\section{Discussion}

About 38 percent of workers in Quebec suffer from work stress, a number which drops to 29 percent for the Rest of Canada. In spite of controlling for a wide range of potential determinants, our regression analyses cannot explain why respondents in Quebec report more work stress than others: we wondered what else might be driving this result. A few possibilities came to mind.

We considered whether individuals have a "portfolio" of stress comprised of both life stress and work stress. Accordingly, if Quebecers have more work stress, perhaps they have less life stress? To examine this possibility, we looked at the life stress question in the CCHS and constructed an indicator which was defined the same way as our work stress variable. Figure 4 graphs this life-stress indicator, and once again we see the plain line depicting respondents in Quebec with high life stress hovering above the lines for all of the other provinces. Overall, 34 percent of people in Quebec have high life stress, as opposed to 26 and 24 percent of people in Ontario and the Rest of Canada. A t-test confirms that 
the percentage of workers with high life stress in Quebec is significantly higher than in the Rest of Canada. It would seem, therefore, that the portfolio explanation does not hold up to scrutiny: Quebecers are not trading off work and life stress, they are reporting more of both.

\section{FIGURE 4 HERE}

Given that Quebecers are more likely to report both work stress and life stress, we are left wondering whether what we are observing is a general predisposition to 'complain' (maybe acknowledge more readily their feelings) by residents of this province. To investigate this possibility, we looked into two things. First, the CCHS 2012 contains a Mental Health Survey which asks detailed questions about whether the respondent is worried or anxious and why. From table 7 we see that residents of Quebec are more likely to report being worried about things "more than most people" (72\%) when we compare their responses to those of Ontario $(61 \%)$ or the Rest of Canada (63\%). When asked about why they were worried, Quebecers are more preoccupied with their love life (31\%) when compared to $\operatorname{RoC}(25 \%)$ and about relationships at work or school (19\% versus $17 \%)$. However, they are much less anxious than others on a whole host of other factors listed in this table including finances (40\% versus $50 \%$ elsewhere), physical appearances $(14 \%$ versus 20\%), health, the economy, the environment, and so on.

\section{TABLE 7 HERE}

To push further on the idea that what we might be observing in Quebec is a disposition to report stress, we wondered if there was any evidence of Quebecers experiencing a higher prevalence of 'measurable' stress-related conditions. To this end, we again turned to the CCHS 2012 Mental Health Survey that asked about sleep problems, 
strokes, mental health, heart disease and absence from work; table 8 presents the prevalence of these conditions. Quebecers are less likely to have no sleep problems (33\% versus 37\% in RoC). Not much difference is seen in the prevalence of strokes; they are more likely to report excellent mental health ( $28 \%$ versus $22 \%$ in RoC) and seem just as likely to have heart disease as others (5\% Quebec and Ontario, 4\% RoC). The one place where we see a big difference is when it comes to being absent from the job: $20 \%$ of Quebecers report an absence from their work in the previous week versus $13 \%$ in Ontario and $14 \%$ in the Rest of Canada.

\section{TABLE 8 HERE}

Rather than examining stress either from work or life, we could take a more positive approach and examine 'life satisfaction'. Indeed, Barrington-Leigh (2013) does precisely this using General Social Survey data. He analyzes the evolution of 'satisfaction with life' responses in Quebec from 1985 to 2008, which started off at a much lower level than in other jurisdictions, but then surpassed them by the early 2000s - a phenomenon attributable to the large increase in income in that province. We too ran regressions on life satisfaction using our CCHS samples spanning 2003-2012. ${ }^{3}$ Two different measures of the dichotomous dependent variable were employed: the first was when it took the value one if respondents strongly agreed, agreed, neither agreed nor disagreed, with the statement that they are satisfied with their life, and zero if the respondent disagreed or strongly disagreed with this statement, and the second was when the middle-category (neither agreed nor disagreed) was removed. We found no statistical difference attributable to residents of Quebec, irrespective of how we defined our dependent variable.

\footnotetext{
${ }^{3}$ The detailed regressions for this analysis can be obtained from the authors.
} 
One difference between Quebec and the other nine provinces that is not explicitly taken into account in our analysis, but which affects context, is the legal environment: Quebec is governed by Civil Law whereas Common Law prevails in all other provinces. Is there something about these two systems that might give rise to different levels of stress? We were intrigued by the stark difference in the number of people in Quebec who are worried about their "love life" and "relationships at school or work" compared to respondents elsewhere (table 7). Recall that, compared to those in RoC, people in Quebec are much more likely to be in a common-law marital relationship (31 percent versus 11 percent) rather than being "legally" married (40 percent versus 63 percent). A commonlaw relationship is legally similar to marriage in common law jurisdictions but not in civil law ones. Quebec's civil law has defined marriage as a contract in which both sides have legal obligations toward each other: where there is no contract, as in a common-law relationship, fewer legal obligations result. This means less legal support from the system in the case of couple separation, which arguably increases stress because of the lack of good "property and inheritance rights" (Beaujot et al., 2013 p. 223). Stress at home can spill over to stress at work.

Another element that is related to the marital-family situation is the Quebec universal child care program implemented in 1997 whereby child care became available at the cost of $\$ 5$ a day (increased to $\$ 7$ in 2004) to all children aged four years old and under. In analysing this policy, Baker et al. (2008) and Kotellenberg and Lehrer (2013) found that it led to a significant increase in both the use of child care and in the labour force participation of mothers, normally considered as positive outcomes since they were the major goals of the program. However, negative effects on the children and their mothers 
were detected. Specifically, the program was associated with a decline in child health and development, and to depression and stress.

We ran several models with interactive terms to see whether more stress at work was associated with different familial arrangements in Quebec; three are reported in table 9. The first point to note is that, even with the interactions, the Quebec dummy variable is always positive and statistically significant. The estimated coefficient on Quebec is always larger for men than for women, with not much difference across the three specifications reported in table 9 by gender. The first two columns report the specification which includes an interaction between province and the presence of a common-law marital relationship. This interactive term is positive and statistically significant for both men and women in Quebec: common-law relationships in that province are associated with reporting more work stress when compared to RoC. Women in such relationships are more likely to report work stress than men, even in Ontario. From these results, we can conclude that commonlaw relationships are associated with work stress for women in Quebec and Ontario, and are associated with much more work stress for men in Quebec than men in Ontario.

\section{TABLE 9 HERE}

The second specification reported in table 9 includes interactive terms between province and being a single parent. We find that being a single parent, either male or female, in Quebec is associated with a great deal more work stress than in the Rest of Canada. No such statistically significant relationship is found for Ontario. Finally, we interact the presence of children under the age of five, and aged 6 to 11 , with province by gender - reported in the last two columns of table 9. Once again, we find that it is only in Quebec that the presence of children, specifically young ones under the age of five, is 
associated with work stress. The interactive terms for Ontario are statistically insignificant. These results certainly suggest that being a single parent in Quebec, or having young children in Quebec, is more stressful than in other provinces. We cannot say definitely why - but it certainly could be related to the encouragement that 'cheap' daycare may have on labour-market participation decisions. Even with these interactive terms, the estimated coefficient on Quebec remains positive and persistently important.

The Francophone work environment culture might be another factor that helps to explain the difference between Quebec and the Rest of Canada in the level of reported work stress. Hofstede (1984) notes that some cultures, like the French and the Spanish ones, adhere to high power distance relationships at work, while low power distance is customary in other cultures, such as found with Anglo-Saxons. ${ }^{4}$ Liu and Spector (2005) argue that people have to obey the rules of others in cultures with high power distances and that this serves to increase the level of stress at work. In low power distance cultures, there is more equal distribution of power which is less stressful. Quebec's culture is arguably similar to that of the French in this regard; it might adhere to high power distances whereas the Rest of Canada is more similar to the Anglo-Saxon approach with low power distance at work. One case in point is that French-speakers have to decide whether to address their bosses and co-workers with the familiar "tu" or the formal "vous", a choice that has long been eliminated in English.

The Quebec economy used to be controlled by Anglo-Protestant employers who were culturally very different from the French Canadian workers. Those workers did not

\footnotetext{
${ }^{4}$ Hofstede (1984) categorizes cultures of Australia, Canada, Great Britain, Ireland, New Zealand and USA as high individualism, low power distance, high masculine and with low uncertainty avoidance; and categorizes cultures like those in France and Spain as high individualism, high power distance, high feminine and with high uncertainty avoidance.
} 
identify with the organizations for which they worked putting pressures on them that could increase stress. This was not the case for workers who were more culturally similar to their employers. Of course, this situation has changed and French Canadians now have more control of their economy. However, as Nunn (2012) argues, the impacts of culture on economic behaviour often persist for very long periods. Liu and Spector (2005) further suggest that workers in high power distance environments might tend to use emotionfocused strategies, like convincing themselves that they have to accept the bad conditions, rather than problem-focused strategies, (like talking to supervisors and find solutions for causes of stress) to deal with work stress. Once again, if we look at the results reported in table 6 which included additional details about the work environment, factors such as workplace social support seem to play a role in explaining part of the estimated coefficient on the Quebec dummy variable - the estimate in column (4) which includes such factors is 0.066 as opposed to 0.081 for the main specification. Nevertheless, workplace culture certainly does not explain all of this difference.

\section{Conclusions}

Residents of Quebec report more work (and life) stress than others and our regression analyses cannot explain away this effect. Quebecers worry about different things when compared to residents of other provinces, but their prevalence of stress-related disorders is not wildly different from others, except that they are much more likely to miss work in any given week. The Civil Law legal regime may explain why individuals in common-law marital relationships report more stress than those in Common Law regimes. Inexpensive day care may explain in part why single parents and those with young children in that province are more likely to report work stress. The Francophone culture may 
partially explain work stress. Maybe the fact that Quebecers pay more income taxes than most other jurisdictions in Canada means that they feel 'justified' in complaining more? Nevertheless, the finding that residents in Quebec report more work stress is persistent. It may well be that there is a tendency for Quebecers to acknowledge more stress than others (Vézina et al., 2010). Even if this is the case, this tendency leads to more employee absenteeism when compared to the Rest of Canada. And this is a real phenomenon with real costs.

Identifying the phenomenon is the first step to coming up with policy solutions. If Quebecers perceive more stress (or acknowledge more stress) than others, can programs be implemented to validate employee concerns? Paying high income taxes may mean that employees feel more 'entitled' to certain benefits - there may be an expectation that the state (province) implement policies that help them with work-place stress. Obviously, small employers would be less able to provide additional benefits of this nature, but larger ones may do well to acknowledge the existence of stress and provide (potentially) means of alleviating it. Provincial programs highlighting the cost of stress and absenteeism can illuminate the potential problems associated therefrom, which may help too. In addition, this research highlights several other factors related to work stress, such as mental health, and lifestyle choices like smoking and drinking. Sensitizing employers (and employees) to this link may be a good first step in trying to unpack the problem of high (at least perceived) worker stress.

One of the advantages of this present study is that it relies on large data sets which help to illuminate the factors influencing reported stress. But the CCHS surveys are not perfect. They cannot address the extent to which either the legal regime or work culture 
explains what is going on in Quebec. It could have been useful to examine the impact of occupation on work stress, but we could not because the information was not available. Our sense is that work stress in small workplaces might be quite different than in larger ones, and the expectations of employees as to what their employer can offer them from the benefit perspective are different too. Data on the size of the workplace coupled with stress levels would help elucidate this part of the puzzle. Information on the differences in the level of stress between Quebec and the Rest of Canada over a longer period, such as that before and after the Quiet Revolution of the 1960's in Quebec, would also be useful. But the CCHS surveys were only available for the period 2001-2012.

More and better data might help solve the puzzle of what is going on in Quebec. We hope that the work done thus far helps to spur on this research agenda. Given the important financial costs of work stress noted in the introduction of this paper, investing potential policy actions to help reduce these costs would be worthwhile. 


\section{References}

Baker, Michael, Jonathan Grubber and Kevin Milligan. 2008. "Universal child care, maternal labor supply and family well-being." Journal of Political Economy, 116(4): 709745 .

Barling, Julian, E. Kevin Kelloway and Michael Robert Frone. 2005. "Handbook of work stress." SAGE Publications, Inc.

Barnes-Farrell, Janet L. 2005. "Chapter 18: older workers" in Barling, Julian, E. Kevin Kelloway and Michael R. Frone. 2009. "Handbook of work stress." SAGE Publications, Inc., 431-455.

Barrington-Leigh, Christopher. 2013. "Quebec convergence and life satisfaction." Canadian Public Policy, 39(2): 193-219.

Bellavia, Gina M. and Michael K. Frone. 2005. "Chapter 6: work-family conflict." in Barling, Julian, E. Kevin Kelloway and Michael R. Frone. 2009. "Handbook of work stress." SAGE Publications, Inc., 113-149.

Beaujot, Roderic, Ching Jiangqin Du and Zenaida Ravanera. 2013. "Family policies in Québec and the Rest of Canada: implications for fertility, child-care, women's paid work, and child development indicators.” Canadian Public Policy, 39(2): 221-239.

Bernèche, Francine. 2010. "Santé mentale au travail." Institut de la statistique du Québec Direction des statistiques de santé.

Bickford, Melanie. 2005. "Stress in the workplace: a general overview of the causes, the effects, and the solutions." Canadian Mental Health Association, Newfoundland and Labrador Division.

Bordeleau, Monique and Issouf Traoré. 2007. "Étude sur la santé mentale et le bien-être des adultes québécois: une synthèse pour soutenir l'action Enquête sur la santé dans les collectivités canadiennes (cycle 1.2) Institut de la statistique du Québec Santé générale, santé mentale et stress au Québec: Série Enquête sur la santé dans les collectivités canadiennes." Zoom santé: santé et bien-être. Juin 2007; Microlog, 2010-00293.

Burke, Ronald J. and Astrid M. Richardsen. 1990. "Sources of satisfaction and stress among Canadian physicians.” Psychological Reports, 67(3): 1335-1344.

Choenarom, Chanokruthai, Reg Arthur Williams, and Bonnie M. Hagerty. 2005. "The role of sense of belonging and social support on stress and depression in individuals with depression." Archives of Psychiatric Nursing, 19(1): 18-29. 
Connor, Kevin. $\quad 2005 . \quad$ "Patients for jobs; biz plan targets mental health." The Toronto Sun, 36, April 14. In Bickford, Melanie. 2005. "Stress in the workplace: a general overview of the causes, the effects, and the solutions." Canadian Mental Health Association, Newfoundland and Labrador Division.

Cooper, Cary L. 1998. "Theories of organizational stress." Oxford University Press, Oxford.

Crompton, Susan. 2011. "What's stressing the stressed? Main sources of stress among workers." Canadian Social Trends, Component of Statistics Canada Catalogue no. 11-008$\mathrm{X}$.

Dolan. Simon L. 2007. "Stress, self-esteem, health and work." Palgrave Macmillan, New York.

Fenwick, Rudy and Mark Tausig. 1994. "The Macroeconomic context of job stress." Journal of Health and Social Behavior, 35(3): 266-282.

Heisz, Andrew and Sébastien LaRochelle-Côté. 2006. "Work hours instability in Canada." Analytical Studies Branch Research Paper Series, Catalogue no. 11F0019MIENo. 278, ISSN: 1205-9153, ISBN: 0-662-43080-8.

Hendrix, William H., Timothy P. Summers, Terry L. Leap and Robert P. Steel. 1995. "Antecedents and organizational effectiveness outcomes of employee stress and health." In Crandall, Rick and Pamela L. Perrewé. 1995. "Occupational stress: a handbook." Philadelphia, PA, US: Taylor \& Francis: 73-92.

Hofstede, Geert H.. 1984. "Culture's consequences: international differences in work related values." (Abridged ed.). Beverly Hills, CA: SAGE.

Liu, Cong and Paul E. Spector. 2005. "Chapter 20: international and cross cultural issues." in Barling, Julian, E. Kevin Kelloway and Michael R. Frone. 2005. "Handbook of work stress." SAGE Publications, Inc., 487-517.

Michie, Susan. 2002, "Causes and management of stress at work." Occupational and Environmental Medicine, 59(1): 67-72.

Nunn, Nathan. 2912, "Culture and Historical Process." Economic History and Developing Regions, 27 (S1): S108-S126.

Park, Jungwee. 2007. "Work stress and job performance." Perspectives, Statistics Canada Catalogue no. 11-008-X: 5-17.

Park, Jungwee. 2008. "A profile of the Canadian forces." Perspectives on Labour and Income, 20(3): 39-52. 
Probst, Tahira M.. 2005. "Chapter 11: economic stressors.” in Barling, Julian, E. Kevin Kelloway and Michael R. Frone. 2005. "Handbook of work stress." SAGE Publications, Inc., 267-299.

Summers, Timothy P., Thomas A. DeCotiis and Angelo S. DeNisi. 1995. "A field study of some antecedents and consequences of felt job stress." In Crandall, Rick and Pamela L. Perrewé. 1995. "Occupational stress: a handbook." Philadelphia, PA, US: Taylor \& Francis: $113-128$.

Surti, Noopur and Riddhi Ambavale. 2013. "A study on stress level of sales employees in garment retail stores of Ahmedabad city." International Journal of Management and Social Sciences Research, 2(6): 31-37.

Tézli, Annette and Anne H. Gauthier. 2009. "Balancing work and family in Canada: an empirical examination of conceptualizations and measurements." Canadian Journal of Sociology, 34(2): 433-462.

Triandis, Harry C.. 1995. "Individualism and collectivism." Boulder, CO: Westview.

Vézina, Michel, Renée Bourbonnais, Alain Marchand and Robert Arcand. 2010. "Self-assessment of stress in the workplace: a misleading health indicator." Perspectives interdisciplinaires sur le travail et la santé, 12(2): 1-11.

Wilkins, Kathryn and Marie P. Beaudet. 1998. "Work stress and health." Health Reports, 10(3): 47-62.

Williams, Cara. 2003. "Sources of workplace stress." Perspective of Labour and Income, 4(6): 23-30. 


\section{Figures and Tables}

Figure1. Work stress over time -provinces

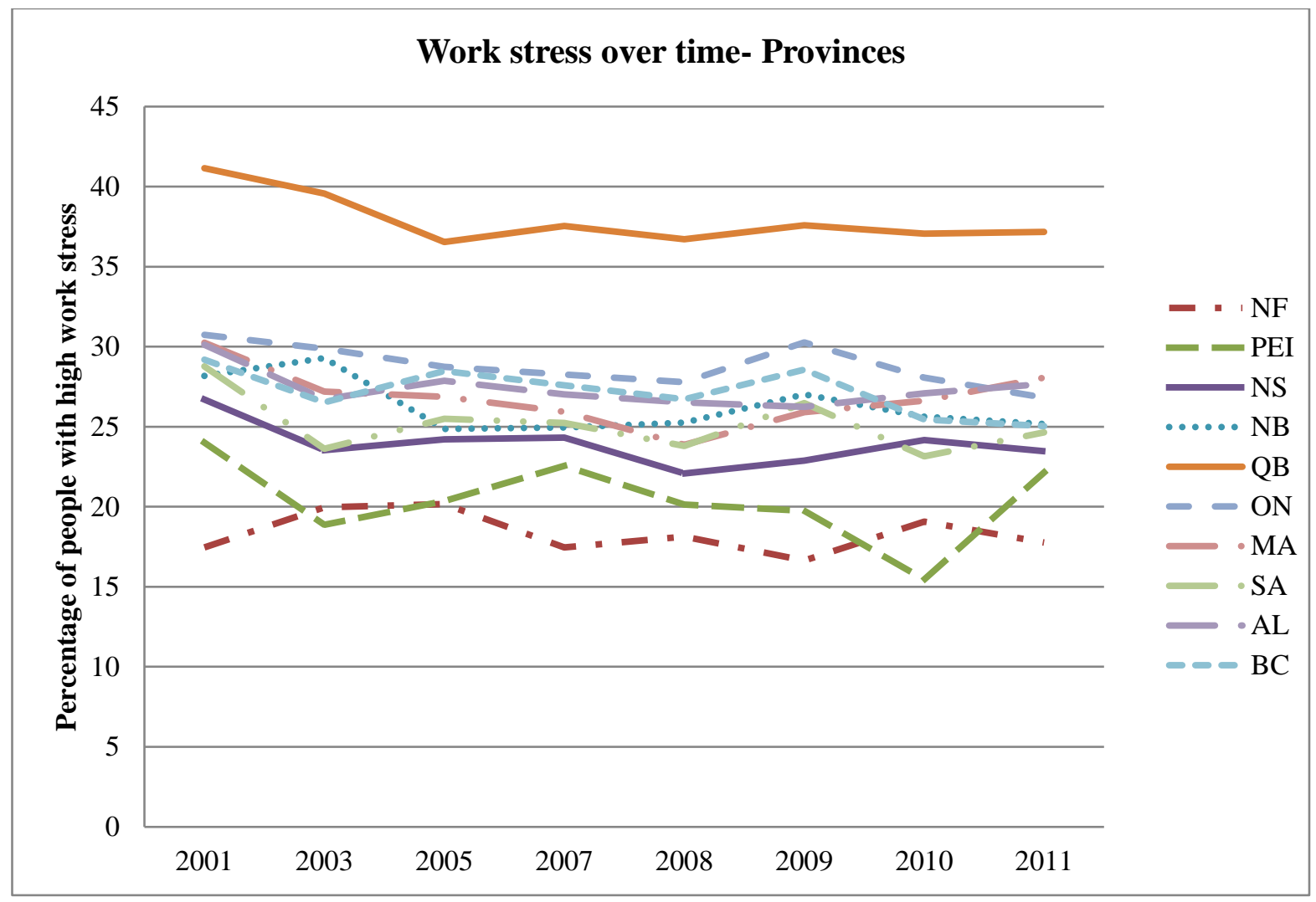

Source: CCHS 2001, 2003, 2005, 2007, 2008, 2009, 2010, 2011 and 2012. 
Figure 2: Gender and work stress (2001-2012)

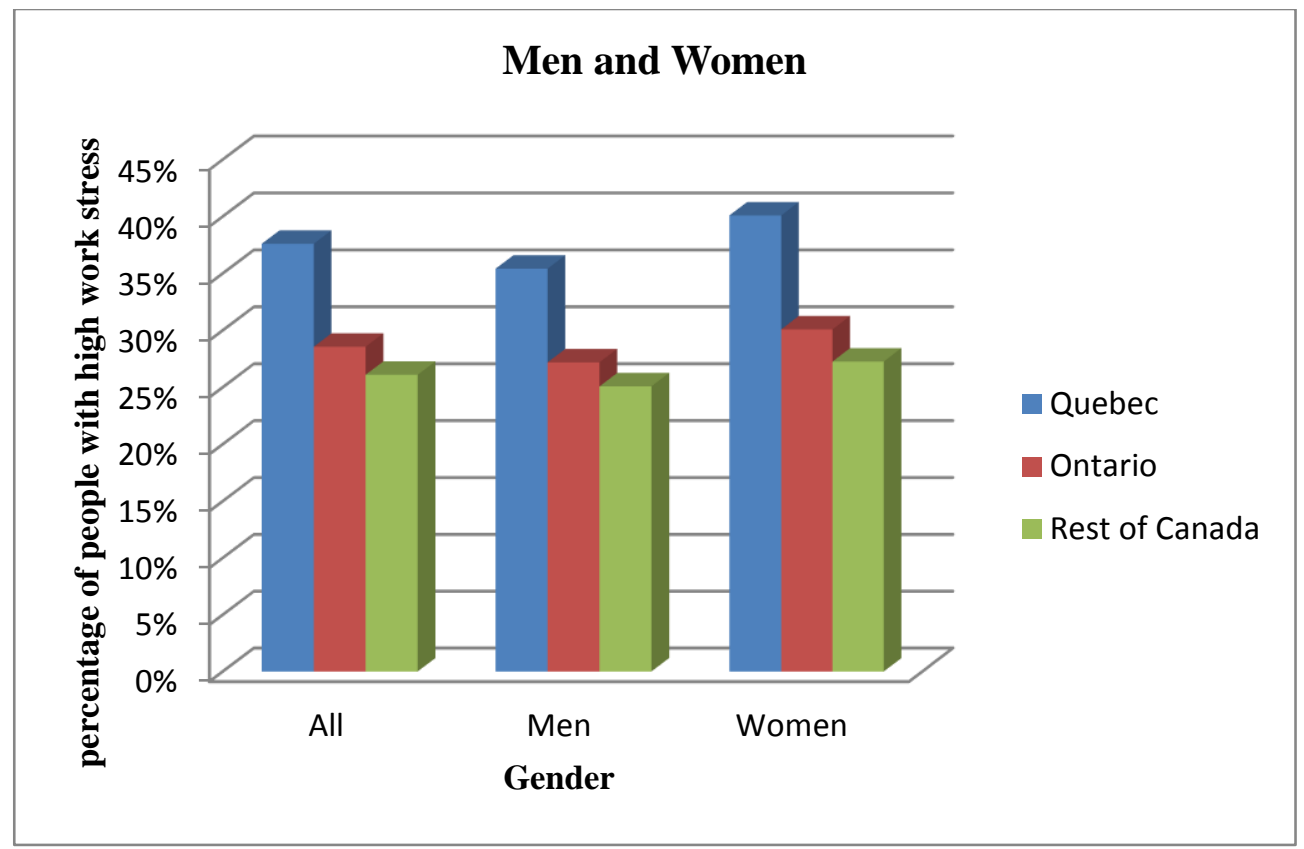

Source: CCHS 2001, 2003, 2005, 2007, 2008, 2009, 2010, 2011 and 2012.

Figure 3: Income and work stress (2001-2012)

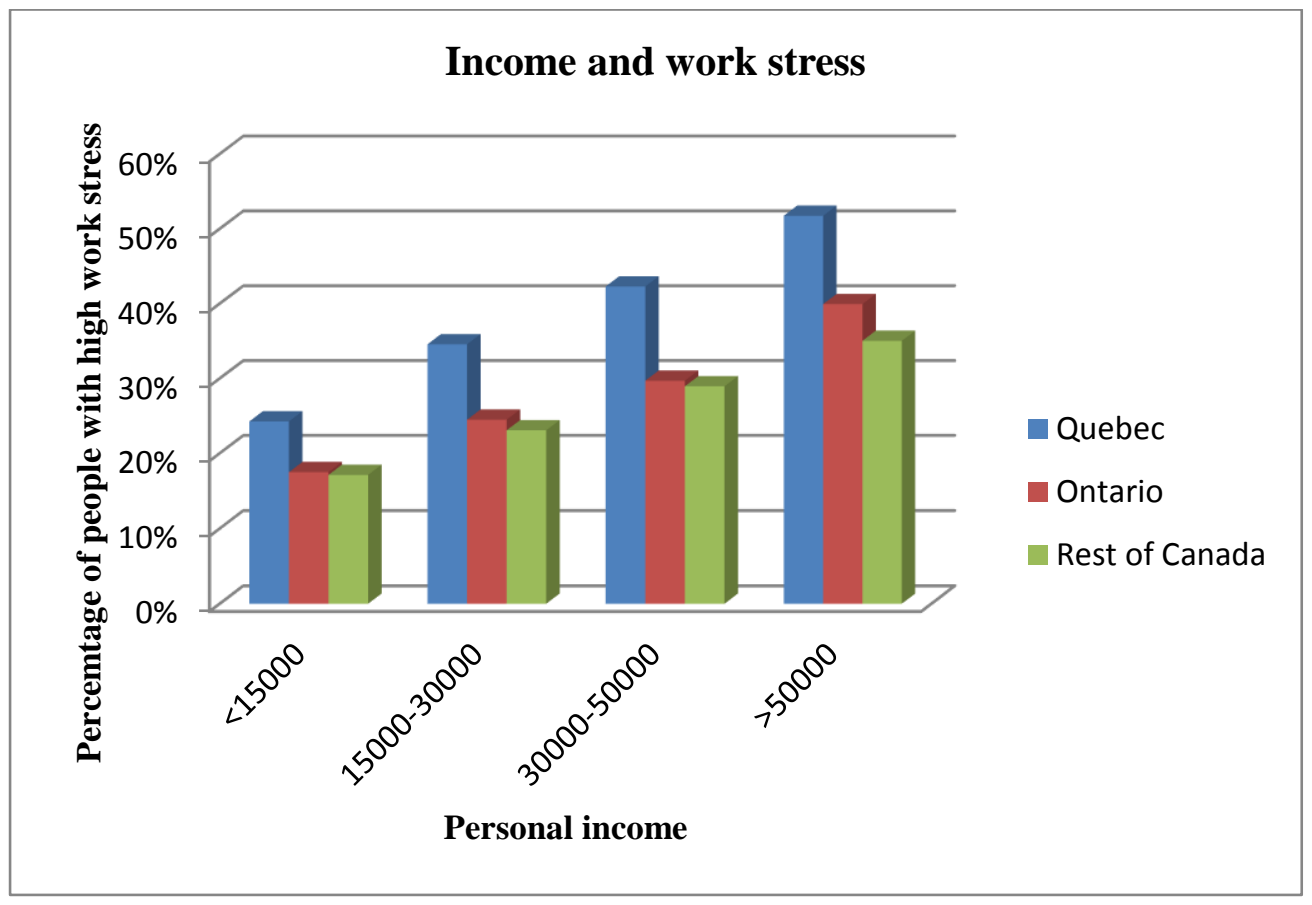

Source: CCHS 2001, 2003, 2005, 2007, 2008, 2009, 2010, 2011 and 2012. 
Figure 4: Workers' life stress over time - provinces

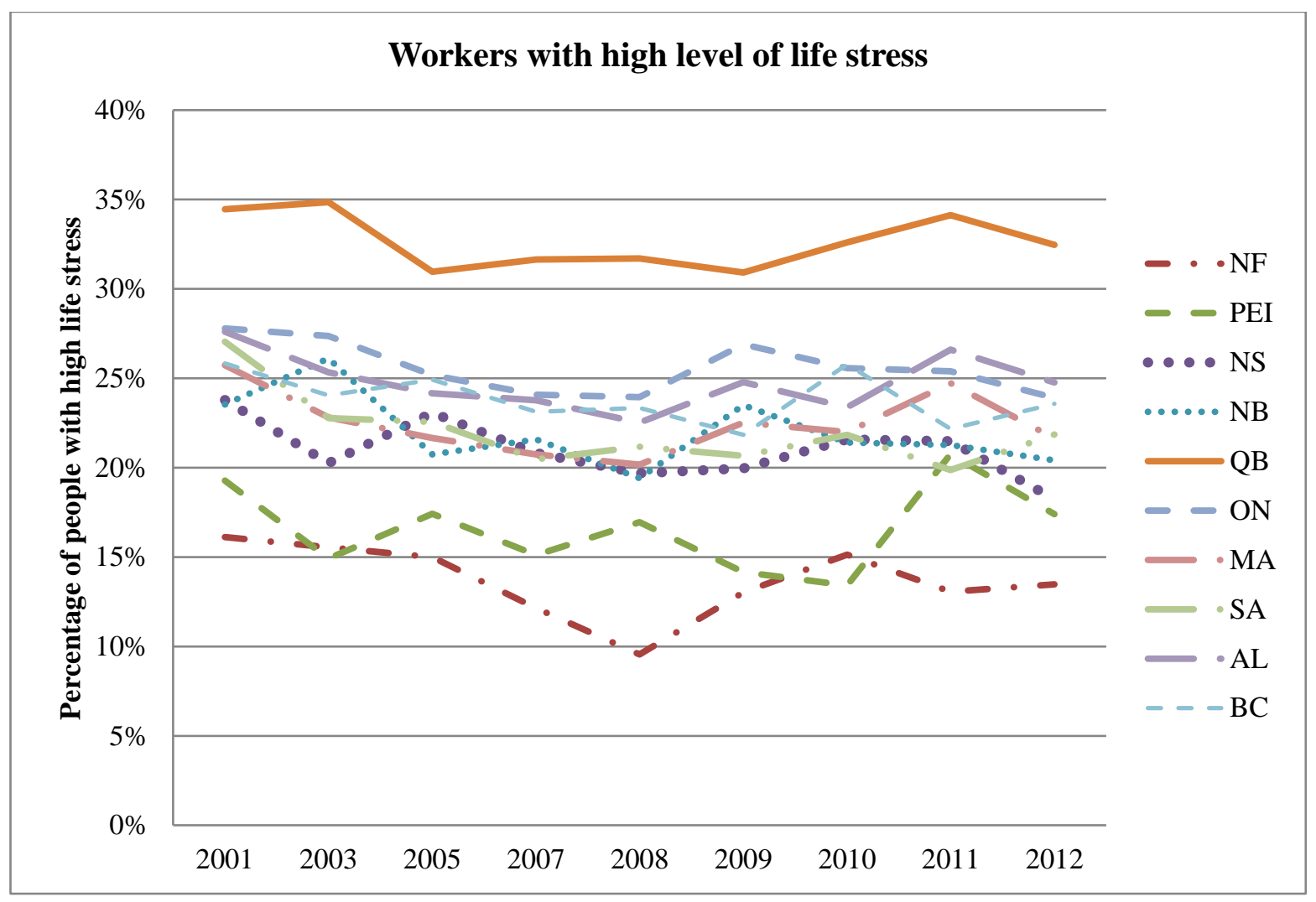

Source: CCHS 2001, 2003, 2005, 2007, 2008, 2009, 2010, 2011 and 2012. 
Table 1: Mean values of some selected characteristics, weighted

\begin{tabular}{|c|c|c|c|c|c|c|c|c|}
\hline Number of Observations: & 259,841 & 131,905 & 127,936 & 75,224 & 184,617 & 54,739 & 88,888 & 116,214 \\
\hline & All & Men & Women & $\begin{array}{l}\text { People with } \\
\text { high work } \\
\text { stress }\end{array}$ & $\begin{array}{l}\text { People with } \\
\text { low work } \\
\text { stress }\end{array}$ & Quebec & Ontario & $\begin{array}{l}\text { Rest of } \\
\text { Canada }\end{array}$ \\
\hline High level of work stress & 0.300 & 0.284 & 0.318 & 1 & 0 & 0.378 & 0.287 & 0.264 \\
\hline \multicolumn{9}{|l|}{ Regional variables } \\
\hline Quebec & 0.236 & 0.236 & 0.236 & 0.297 & 0.209 & & & \\
\hline Ontario & 0.398 & 0.396 & 0.400 & 0.380 & 0.405 & & & \\
\hline Rest of Canada & 0.366 & 0.368 & 0.364 & 0.323 & 0.386 & & & \\
\hline CMA & 0.707 & 0.704 & 0.710 & 0.726 & 0.699 & 0.698 & 0.799 & 0.612 \\
\hline \multicolumn{9}{|l|}{ Personal characteristics } \\
\hline male & 0.539 & 1.000 & 0.000 & 0.511 & 0.551 & 0.539 & 0.537 & 0.542 \\
\hline age & 39.6 & 40.1 & 39.0 & 40.8 & 39.1 & 39.3 & 39.6 & 39.7 \\
\hline $\begin{array}{l}\text { Less than secondary school } \\
\text { (reference: Secondary school) }\end{array}$ & 0.106 & 0.121 & 0.089 & 0.078 & 0.118 & 0.118 & 0.100 & 0.105 \\
\hline $\begin{array}{l}\text { Some post-secondary } \\
\text { (reference: secondary school) }\end{array}$ & 0.087 & 0.085 & 0.089 & 0.070 & 0.094 & 0.085 & 0.083 & 0.092 \\
\hline $\begin{array}{l}\text { Post-secondary } \\
\text { (reference: secondary school) }\end{array}$ & 0.643 & 0.627 & 0.663 & 0.715 & 0.613 & 0.674 & 0.644 & 0.623 \\
\hline Visible minority (reference: white) & 0.167 & 0.169 & 0.164 & 0.142 & 0.177 & 0.092 & 0.231 & 0.144 \\
\hline $\begin{array}{l}\text { Immigrants } \\
\text { (reference: non-immigrants) }\end{array}$ & 0.214 & 0.221 & 0.205 & 0.203 & 0.219 & 0.124 & 0.299 & 0.179 \\
\hline Mother tongue: English only & 0.582 & 0.581 & 0.582 & 0.535 & 0.602 & 0.070 & 0.692 & 0.791 \\
\hline $\begin{array}{l}\text { Mother tongue: French / French and English } \\
\text { (reference: English) }\end{array}$ & 0.232 & 0.228 & 0.236 & 0.292 & 0.206 & 0.819 & 0.051 & 0.050 \\
\hline $\begin{array}{l}\text { Mother tongue: neither English nor French } \\
\text { (reference: English) }\end{array}$ & 0.187 & 0.191 & 0.182 & 0.173 & 0.193 & 0.112 & 0.256 & 0.159 \\
\hline
\end{tabular}


Hours worked main job

Full time/part time student

(reference: non-students)

Constant dollar personal income (\$000)

\section{Family characteristics}

Married

(reference: single)

Common-law

(reference: single)

Separated/widowed/divorced

(reference: single)

Children less than 5

Children 6-11

\section{Health and personal behaviour characteristics}

Health: Poor or fair

(reference: excellent/very good/good)

Mental health: Poor or fair

(reference: excellent/very good/good)

Physical activity index: moderate or inactive

(reference: active)

Type of smoker: daily or occasionally

(reference: not at all)

Type of drinker: regular

(reference: former/never/occasional)

Sense of belonging to community: weak or very weak

(reference: strong or very strong)

\begin{tabular}{|c|c|c|c|c|c|c|c|}
\hline 35.8 & 39.1 & 32.0 & 39.9 & 34.1 & 34.3 & 36.1 & 36.5 \\
\hline 0.141 & 0.126 & 0.159 & 0.105 & 0.156 & 0.153 & 0.147 & 0.126 \\
\hline 40.7 & 48.5 & 31.5 & 49.5 & 36.9 & 36.2 & 42.7 & 41.4 \\
\hline 0.531 & 0.552 & 0.506 & 0.549 & 0.523 & 0.371 & 0.582 & 0.578 \\
\hline 0.142 & 0.139 & 0.145 & 0.168 & 0.131 & 0.291 & 0.086 & 0.107 \\
\hline 0.071 & 0.048 & 0.097 & 0.082 & 0.066 & 0.074 & 0.070 & 0.070 \\
\hline 0.165 & 0.172 & 0.157 & 0.174 & 0.161 & 0.163 & 0.169 & 0.163 \\
\hline 0.122 & 0.113 & 0.132 & 0.129 & 0.118 & 0.115 & 0.130 & 0.117 \\
\hline 0.061 & 0.061 & 0.061 & 0.076 & 0.055 & 0.047 & 0.064 & 0.067 \\
\hline 0.038 & 0.034 & 0.044 & 0.057 & 0.030 & 0.028 & 0.040 & 0.043 \\
\hline 0.730 & 0.708 & 0.756 & 0.750 & 0.722 & 0.779 & 0.727 & 0.702 \\
\hline 0.235 & 0.256 & 0.210 & 0.253 & 0.227 & 0.264 & 0.227 & 0.225 \\
\hline 0.713 & 0.776 & 0.640 & 0.743 & 0.701 & 0.788 & 0.685 & 0.696 \\
\hline 0.371 & 0.373 & 0.369 & 0.408 & 0.355 & 0.464 & 0.349 & 0.335 \\
\hline
\end{tabular}

Source: CCHS, 2003 -2012 
Table 2. Work stress regression, probit model, pooled CCHS (20032012). Dependent variable: high work stress

\section{Provincial variable (ref: rest of Canada)}

Quebec

$0.081 * * *$

(0.008)

Ontario

CMA (ref : non-CMA)

$0.019 * * *$

(0.004)

$0.022 * * *$

(0.003)

\section{Personal}

\section{characteristics}

Male

$-0.079 * * *$

(0.004)

Age

Age squared

Education (ref: secondary school)

Less than secondary school

$-0.005$

(0.007)

Some post-secondary

$0.013^{*}$

(0.007)

Post-secondary

$0.048 * * *$

(0.005)

Visible minority

$-0.031 * * *$

$(0.007)$

Immigrants

0.010

(0.007)

Mother tongue (ref: English)

French

$0.053 * * *$

(0.007)

Neither English nor French

(0.007)

\section{Work characteristics}

Hours worked main job $\quad 0.004 * * *$

(0.0001)

Full time/part time student

$0.037 * * *$

(0.006)

Constant dollar pers. income

(\$000)

$0.001 * * *$

$(0.00006)$

\section{Family}

characteristics

Marital status (ref: single)

Married

0.009*

(0.005)

Common-law

$0.020 * * *$

(0.006)

Separated/widow/divorced

$0.021 * *$

(0.008)

Children (ref: no children)

Children less than 5

0.00002

(0.005)

Children 6-11

$-0.003$

(0.006)

\section{Health and personal} behaviour

\section{Health Poor or fair (ref:}

$0.084 * * *$

excellent/very good/good)

(0.008)

Mental health: Poor or fair (ref: $0.160 * * *$ excellent/good/very good)

(0.010)

Physical activity: moderate or $\quad 0.006$

inactive (ref: active)

(0.004)

Type of smoker: daily or $0.033 * * *$ occasionally (ref: not at all) 
Type of drinker: regular $\quad(0.004)$ (ref: former/ never/ occasional)

$\begin{array}{ll}\text { Sense of belonging to } & 0.030 * * * \\ \text { community: weak or very weak } & (0.004) \\ \text { (ref: strong or very strong) } & \end{array}$
Year fixed effect (ref : 2003)

2005

$-0.002$

$(0.004)$

$-0.005$

$(0.005)$

$-0.013^{* *}$

$(0.005)$

0.002

$(0.006)$

$-0.010$

$(0.007)$

$-0.018 * * *$

$(0.006)$

$-0.029 * * *$

$(0.007)$

Observations $\quad 259841$

R-squared $\quad 0.060$

Robust standard errors in parentheses. $* * * \mathrm{p}<0.01, * * \mathrm{p}<0.05, * \mathrm{p}<0.1$

Sample weights are used in these regressions. The weights are normalized for each survey to add up to one. 


\begin{tabular}{lllllll}
\multicolumn{6}{c}{ Table 3. Work stress regression, probit model, effect of Quebec and } \\
Ontario for various specifications and by gender, pooled CCHS (2003- \\
2012). Dependent variable: high work stress
\end{tabular}

\section{Control variables}

\begin{tabular}{|c|c|c|c|c|c|c|}
\hline $\begin{array}{l}\text { Personal } \\
\text { characteristics }\end{array}$ & Yes & Yes & Yes & Yes & Yes & Yes \\
\hline $\begin{array}{l}\text { Work } \\
\text { characteristics }\end{array}$ & No & Yes & Yes & Yes & Yes & Yes \\
\hline $\begin{array}{l}\text { Family } \\
\text { Charactetistics }\end{array}$ & No & No & Yes & Yes & Yes & Yes \\
\hline $\begin{array}{l}\text { Health and } \\
\text { behaviour }\end{array}$ & No & No & No & Yes & Yes & Yes \\
\hline $\begin{array}{l}\text { Year fixed } \\
\text { effects }\end{array}$ & Yes & Yes & Yes & Yes & Yes & Yes \\
\hline Observations & 259841 & 259841 & 259841 & 259841 & 131905 & 127936 \\
\hline R-squared & 0.030 & 0.051 & 0.052 & 0.059 & 0.056 & 0.067 \\
\hline
\end{tabular}

Robust standard errors in parentheses. $* * * \mathrm{p}<0.01, * * \mathrm{p}<0.05, * \mathrm{p}<0.1$

Sample weights are used in these regressions. The weights are normalized for each survey to add up to one. The variables in each of the characteristics are those shown in table 2. 


\section{Table 4. Work stress regression, probit model, effect of Quebec and Ontario for various subgroups, pooled CCHS (2003-2012). Dependent variable: high work stress}

\begin{tabular}{llllll}
\hline $\begin{array}{l}\text { Province } \\
\text { variable (ref : } \\
\text { rest of Canada) }\end{array}$ & $\begin{array}{l}\text { All } \\
(1)\end{array}$ & $\begin{array}{l}\text { Immigrants } \\
(2)\end{array}$ & $\begin{array}{l}\text { Non-immigrants } \\
(3)\end{array}$ & $\begin{array}{l}\text { Anglophones } \\
(4)\end{array}$ & $\begin{array}{l}\text { Francophones } \\
(5)\end{array}$ \\
Québec & $0.081^{* * *}$ & $0.046^{* * *}$ & $0.095^{* * *}$ & $0.069^{* * *}$ & $0.103^{* * *}$ \\
& $(0.008)$ & $(0.016)$ & $(0.008)$ & $(0.017)$ & $(0.011)$ \\
Ontario & $0.019^{* * *}$ & $0.018^{*}$ & $0.019^{* * *}$ & $0.014 * *$ & 0.025 \\
& $(0.004)$ & $(0.009)$ & $(0.004)$ & $(0.004)$ & $(0.016)$ \\
& & & & & 61726 \\
Observations & 259841 & 33743 & 226098 & 167992 & 0.062 \\
R-squared & 0.059 & 0.047 & 0.063 & 0.053 & \\
\hline
\end{tabular}

Robust standard errors in parentheses. $* * * \mathrm{p}<0.01, * * \mathrm{p}<0.05,{ }^{*} \mathrm{p}<0.1$

Sample weights are used in these regressions. The weights are normalized for each survey to add up to one.

All the regressions control for personal characteristics, work characteristics, family characteristics, health and behavioural characteristics, and year fixed effects as shown in table 2 . 


\section{Table 5. Work stress regression, probit model, effect of Quebec and Ontario for Quebec regions, pooled CCHS (2003-2012). Dependent variable: high work stress}

\begin{tabular}{llllllll}
\hline $\begin{array}{l}\text { Province } \\
\text { variable (ref : rest } \\
\text { of Canada) }\end{array}$ & $\begin{array}{l}\text { All } \\
\text { regions } \\
(1)\end{array}$ & $\begin{array}{l}\text { Saguenay } \\
(2)\end{array}$ & $\begin{array}{l}\text { Quebec City } \\
(3)\end{array}$ & $\begin{array}{l}\text { Sherbrooke } \\
(4)\end{array}$ & $\begin{array}{l}\text { Trois- } \\
\text { Rivières } \\
(5)\end{array}$ & $\begin{array}{l}\text { Montreal } \\
(6)\end{array}$ & $\begin{array}{l}\text { Non CMA } \\
(7)\end{array}$ \\
Region in Québec & $\begin{array}{l}0.081^{* * *} \\
\text { (0.008) }\end{array}$ & $\begin{array}{l}0.092^{* * *} \\
(0.019)\end{array}$ & $\begin{array}{l}0.103^{* * *} \\
(0.013)\end{array}$ & $\begin{array}{l}0.072^{* * *} \\
(0.020)\end{array}$ & $\begin{array}{l}0.086^{* * *} \\
(0.021)\end{array}$ & $\begin{array}{l}0.086^{* * *} \\
(0.009)\end{array}$ & $\begin{array}{l}0.068^{* * *} \\
(0.010)\end{array}$ \\
Ontario & $0.019^{* * *}$ & $0.018^{* * *}$ & $0.018^{* * *}$ & $0.018^{* * *}$ & $0.018^{* * *}$ & $0.019^{* * *}$ & $0.029^{* * *}$ \\
& $(0.004)$ & $(0.004)$ & $(0.004)$ & $(0.004)$ & $(0.004)$ & $(0.004)$ & $(0.005)$ \\
& & & & & & & $2004)$ \\
Observations & 259841 & 206839 & 210145 & 206672 & 206627 & 21912 & 131448 \\
R-squared & 0.060 & 0.052 & 0.054 & 0.052 & 0.052 & 0.058 & 0.059 \\
\hline
\end{tabular}

Robust standard errors in parentheses. $* * * \mathrm{p}<0.01, * * \mathrm{p}<0.05,{ }^{*} \mathrm{p}<0.1$

Sample weights are used in these regressions. The weights are normalized for each survey to add up to one.

All the regressions control for personal characteristics, work characteristics, family characteristics, health and behavioural characteristics, and year fixed effects as shown in table 2. 


\section{Table 6: Work stress regression, probit model, effect of Quebec and Ontario, sensitivity analysis with additional variables,_various cycles of CCHS (2003-2012).}

\begin{tabular}{|c|c|c|c|c|c|c|c|c|}
\hline $\begin{array}{l}\text { Province } \\
\text { variable (ref : } \\
\text { rest of Canada) }\end{array}$ & (1) & (2) & (3) & (4) & (5) & (6) & (7) & (8) \\
\hline Québec & $0.081 * * *$ & $0.077^{* * *}$ & $0.086 * * *$ & $0.066^{* * *}$ & $0.083 * * *$ & $0.044^{* * *}$ & $0.094^{* * *}$ & $0.082^{* * *}$ \\
\hline & $(0.008)$ & $(0.014)$ & $(0.008)$ & $(0.021)$ & $(0.008)$ & $(0.014)$ & $(0.015)$ & $(0.008)$ \\
\hline Ontario & $\begin{array}{l}0.019 * * * \\
(0.004)\end{array}$ & $\begin{array}{l}0.033^{* * *} \\
(0.007)\end{array}$ & $\begin{array}{l}0.021^{* * *} \\
(0.004)\end{array}$ & $\begin{array}{l}0.038^{*} \\
(0.020)\end{array}$ & $\begin{array}{l}0.020^{* * *} \\
(0.004)\end{array}$ & & $\begin{array}{l}0.036 * * * \\
(0.009)\end{array}$ & $\begin{array}{l}0.022^{* * *} \\
(0.004)\end{array}$ \\
\hline Observations & 259841 & 62721 & 238919 & 30436 & 259653 & 42907 & 73664 & 259841 \\
\hline R-squared & 0.060 & 0.067 & 0.069 & 0.160 & 0.061 & 0.062 & 0.064 & 0.059 \\
\hline
\end{tabular}

Robust standard errors in parentheses. *** $\mathrm{p}<0.01, * * \mathrm{p}<0.05, * \mathrm{p}<0.1$

Sample weights are used for those regressions. The weights are normalized for each survey to add up to one.

Specifications of the columns:

1- Controlled just for the variables in table 2 (personal, work, family, and health and behavioural characteristics, and year fixed effects).

2- Controlled also for shift types (regular evening shift, regular night shift, rotating shift, split shift, on call, irregular schedule and Other types of shifts) plus the variables in table 2.

3- Controlled also for working part time plus the variables in table 2.

4- Controlled also for work environment (high strain job, low strain job, active job, job insecurity, physically demanding job, low workplace social support and job dissatisfaction) plus the variables in table 2.

5- Controlled also for mental health problems (mood disorders and anxiety disorders) plus the variables in table 2.

6- Controlled also for social support (tangible support, affective support, positive social support and emotional support) plus the variables in table 2 .

7- Controlled also for availability and quality of health care (availability of health care and Quality of health care) plus the variables in table 2.

8- Controlled also for some provincial information (regional average weekly hours worked, regional average weekly earnings and regional unemployment duration) plus the variables in table 2. 


\begin{tabular}{|c|c|c|c|}
\hline \multicolumn{4}{|c|}{$\begin{array}{l}\text { Table 7: Percentage of worried, nervous and anxious people } \\
\text { who are worried about... (CCHS 2012-mental health survey) }\end{array}$} \\
\hline & QC & ON & ROC \\
\hline Worried - Love life & 31.17 & 23.54 & 25.22 \\
\hline Worried - Relationships at school or work & 18.75 & 14.99 & 16.56 \\
\hline Worried - Agoraphobia & 2.78 & 2.34 & 2.58 \\
\hline Worried - Compulsions & 2.88 & 2.2 & 2.48 \\
\hline Worried - Other & 5.27 & 4.42 & 4.56 \\
\hline Worried - Anxious or worried about everything & 7.26 & 15.41 & 15.44 \\
\hline Worried - Anxious or worried about nothing in particular & 5.89 & 8.94 & 11.42 \\
\hline Worried - Finances & 40.38 & 50.09 & 49.53 \\
\hline Worried - Success at school or work & 31.49 & 35.5 & 38.24 \\
\hline Worried - Social life & 14.67 & 17.17 & 19.76 \\
\hline Worried - Relationships with family & 23.66 & 34.79 & 33.62 \\
\hline Worried - Physical appearance & 13.96 & 19.61 & 20.47 \\
\hline Worried - Own physical health & 16.32 & 26.43 & 29.68 \\
\hline Worried - Own mental health & 11.44 & 14.87 & 17.53 \\
\hline Worried - Alcohol or drug use & 5.74 & 6.69 & 6.11 \\
\hline Worried - Being away from home or apart from loved ones & 15.1 & 15.16 & 19.68 \\
\hline Worried - The health or welfare of loved ones & 29.62 & 36.16 & 36.02 \\
\hline Worried - Social phobias & 5.87 & 9.08 & 9.96 \\
\hline Worried - Specific phobias & 4.64 & 5.24 & 5.71 \\
\hline Worried - Obsessions & 2.47 & 3.4 & 3.95 \\
\hline Worried - Crime / violence & 2.89 & 4.96 & 7.65 \\
\hline Worried - Economy & 5.73 & 11.24 & 13.15 \\
\hline Worried - Environment & 4.72 & 7.32 & 8.78 \\
\hline Worried - Moral decline of society & 5.61 & 9.07 & 10.14 \\
\hline Worried - War / revolution & 3.12 & 4.52 & 5.77 \\
\hline
\end{tabular}


Table 8. Some indicators of the potential consequences of stress: Mental Health Survey, CCHS 2012

\begin{tabular}{|l|c|c|c|}
\hline & Quebec & Ontario & $\begin{array}{l}\text { Rest of } \\
\text { Canada }\end{array}$ \\
\hline Sleep problem ... & & & \\
\hline NONE OF THE TIME & $33 \%$ & $40 \%$ & $37 \%$ \\
\hline A LITTLE OF THE TIME & $28 \%$ & $24 \%$ & $24 \%$ \\
\hline SOME OF THE TIME & $25 \%$ & $22 \%$ & $24 \%$ \\
\hline MOST OF THE TIME & $10 \%$ & $9 \%$ & $10 \%$ \\
\hline ALL OF THE TIME & $3 \%$ & $5 \%$ & $5 \%$ \\
\hline $\begin{array}{l}\text { Stroke-Suffers from the effects of a } \\
\text { stroke? }\end{array}$ & & & \\
\hline Yes & $1.05 \%$ & $1.04 \%$ & $1.07 \%$ \\
\hline Mental health & & & \\
\hline Poor & $1 \%$ & $2 \%$ & $1 \%$ \\
\hline Fair & $4 \%$ & $6 \%$ & $8 \%$ \\
\hline Good & $26 \%$ & $26 \%$ & $29 \%$ \\
\hline Very Good & $28 \%$ & $40 \%$ & $40 \%$ \\
\hline Excellent & & $26 \%$ & $22 \%$ \\
\hline $\begin{array}{l}\text { Absent from job last week- Last week, } \\
\text { did you have a job or business from } \\
\text { which you were absent? }\end{array}$ & & & \\
\hline Yes & $20 \%$ & $13 \%$ & $14 \%$ \\
\hline Has heart disease? & & & \\
\hline Yes & $5 \%$ & $5 \%$ & $4 \%$ \\
\hline
\end{tabular}




\section{Table 9. Work stress regression, probit model, effects of interactions with common- law, sole parenthood and presence of children, by gender, pooled CCHS (2003- 2012). Dependent variable: high work stress}

\begin{tabular}{|c|c|c|c|c|c|c|}
\hline $\begin{array}{l}\text { Province } \\
\text { variable (ref : rest of Canada) }\end{array}$ & Men & Women & Men & Women & Men & Women \\
\hline Quebec & $\begin{array}{l}0.078 * * * \\
(0.010)\end{array}$ & $\begin{array}{l}0.061 * * * \\
(0.011)\end{array}$ & $\begin{array}{l}0.082 * * * \\
(0.010)\end{array}$ & $\begin{array}{l}0.065^{* * *} \\
(0.010)\end{array}$ & $\begin{array}{l}0.077 * * * \\
(0.011)\end{array}$ & $\begin{array}{l}0.059 * * * \\
(0.011)\end{array}$ \\
\hline Ontario & $\begin{array}{l}0.019 * * * \\
(0.005)\end{array}$ & $\begin{array}{l}0.012 * * \\
(0.005)\end{array}$ & $\begin{array}{l}0.018 * * * \\
(0.005)\end{array}$ & $\begin{array}{l}0.016^{* * *} \\
(0.005)\end{array}$ & $\begin{array}{l}0.014 * * \\
(0.006)\end{array}$ & $\begin{array}{l}0.013 * * \\
(0.006)\end{array}$ \\
\hline Common-law & $\begin{array}{l}0.015 \\
(0.012)\end{array}$ & $\begin{array}{l}-0.016 \\
(0.012)\end{array}$ & & & & \\
\hline Quebec*common-law & $\begin{array}{l}0.030^{*} \\
(0.016)\end{array}$ & $\begin{array}{l}0.048 * * * \\
(0.016)\end{array}$ & & & & \\
\hline Ontario*common-law & $\begin{array}{l}-0.005 \\
(0.016)\end{array}$ & $\begin{array}{l}0.043^{* *} \\
(0.017)\end{array}$ & & & & \\
\hline Single parent & & & $\begin{array}{l}-0.061 \\
(0.045)\end{array}$ & $\begin{array}{l}-0.044 \\
(0.027)\end{array}$ & & \\
\hline Quebec*Single parent & & & $\begin{array}{l}0.153 * \\
(0.085)\end{array}$ & $\begin{array}{l}0.072 * \\
(0.043)\end{array}$ & & \\
\hline Ontario*Single parent & & & $\begin{array}{l}0.056 \\
(0.102)\end{array}$ & $\begin{array}{l}0.002 \\
(0.038)\end{array}$ & & \\
\hline Children under 5 & & & & & $\begin{array}{l}-0.016 * \\
(0.009)\end{array}$ & $\begin{array}{l}-0.019 * * \\
(0.009)\end{array}$ \\
\hline Children 6-11 & & & & & $\begin{array}{l}0.006 \\
(0.012)\end{array}$ & $\begin{array}{l}-0.006 \\
(0.011)\end{array}$ \\
\hline Quebec* children under 5 & & & & & $\begin{array}{l}0.035 * * \\
(0.016)\end{array}$ & $\begin{array}{l}0.063^{* * *} \\
(0.016)\end{array}$ \\
\hline Quebec* children 6-11 & & & & & $\begin{array}{l}-0.004 \\
(0.021)\end{array}$ & $\begin{array}{l}-0.008 \\
(0.019)\end{array}$ \\
\hline Ontario* children under 5 & & & & & $\begin{array}{l}0.018 \\
(0.013)\end{array}$ & $\begin{array}{l}0.019 \\
(0.013)\end{array}$ \\
\hline Ontario*children 6-11 & & & & & $\begin{array}{l}0.007 \\
(0.016)\end{array}$ & $\begin{array}{l}0.005 \\
(0.016)\end{array}$ \\
\hline Observations & 131905 & 127936 & 131420 & 127069 & 131905 & 127936 \\
\hline R-squared & 0.062 & 0.081 & 0.061 & 0.081 & 0.062 & 0.082 \\
\hline
\end{tabular}

Robust standard errors in parentheses. $* * * \mathrm{p}<0.01, * * \mathrm{p}<0.05, * \mathrm{p}<0.1$

Sample weights are used in these regressions. The weights are normalized for each survey to add up to one.

All the regressions control for personal characteristics, work characteristics, family characteristics, health and behavioural characteristics, and year fixed effect as shown in Table 2. 